\title{
Viability of compact cities in the post-COVID-19 era: subway ridership variations in Seoul Korea
}

\author{
Daeyoung Kwon ${ }^{1}$ · Sung Eun Sally Oh ${ }^{1}$ · Sangwon Choi ${ }^{1} \cdot$ Brian H. S. Kim ${ }^{1,2} \mathbb{D}$
}

Received: 29 October 2021 / Accepted: 2 February 2022

(C) The Author(s), under exclusive licence to Springer-Verlag GmbH Germany, part of Springer Nature 2022

\begin{abstract}
COVID-19 exposed the vulnerability of compact cities against shock events. As the impact of COVID-19 not only persists, but also expands throughout the world, this study questions whether the compact city model would be sustainable in the postCOVID-19 era. As such, this study examines the dynamics among major COVID19 outbreak events, government interventions, and subway ridership in two compact cities, Seoul and New York City. Then, to gain thorough understanding of the impact of risks on compact urban form, it narrows the scope to Seoul in comparing subway ridership patterns in 2019 and 2020, and identifying characteristics that affect the volatility of subway ridership levels. The results affirm that individual mobility, COVID-19 outbreaks, and government interventions are closely related, and reveal that the extent of social distancing measures in compact cities is limited. This finding aligns with existing literature that link diseases transmission with dense population and mixed land use, accentuating the vulnerability of the compact city model against shocks. As a result, a multidimensional urban planning approach that incorporates polycentric and decentralized urban form is recommended to effectively and sustainably control disease outbreaks in compact cities.
\end{abstract}

JEL Classification R12 $\cdot$ R14 $\cdot$ R49

Brian H. S. Kim

briankim66@snu.ac.kr

1 Program in Regional Information, Department of Agricultural Economics and Rural Development, Seoul National University, 1 Gwanangno, Gwanak-gu, Seoul 08826, Republic of Korea

2 Program in Agricultural and Forest Meteorology, Research Institute of Agriculture and Life Sciences, Seoul National University, 1 Gwanangno, Gwanak-gu, Seoul 08826, Republic of Korea 


\section{Introduction}

By mid-December 2020, Coronavirus disease 2019 (COVID-19) cases reached about 70.4 million cases, and COVID-19-induced deaths totaled about 1.6 million (WHO 2020). The impact of the pandemic reached far beyond physical and mental health risks, disrupting employment and education systems that further jeopardized the health of the global economy (Abodunrin et al. 2020; Brodeur et al. 2021; Polyakova et al. 2020; Scull et al. 2020). Facing rent and housing cost burdens as a result of the economic recession, companies and individuals relocated away from cities like New York City (NYC), where the vacancy rate far exceeded that of the post-2008 Economic Recession and of post-September 11 attacks (Bahney 2020; Clarke 2020; Creswell and Eavis 2020; Grant and Tucker 2020). Other megacities have undergone similar phenomena, aggravated by the damages of COVID-19 on the real estate market and other sectors.

The global response to mitigating the impact of COVID-19 has been diverse, ranging from mobility restrictions like lockdowns to less restricting versions like social distancing. For instance, whereas countries with drastically high COVID19 cases like the USA, India, and Brazil implemented lockdowns to slow the spread of the virus, South Korea administered various disease control measures such as social distancing, drive-through testing, and contract tracing to slow the disease's spread at an early stage. Despite these attempts to control the pandemic, however, COVID-19 cases continued to surge across the world.

Metropolitan cities, in particular, have been subject to large-scale COVID-19 outbreaks, suggesting that population density may be closely related to disease transmission. Many modern metropolitan cities follow the compact city model that typically features high residential density and mixed land use. The compact city model offers benefits like shorter commuting time, reduced environmental damage, and less fossil fuel and energy consumption while lowering vehicle dependency and infrastructure demand. However, it is founded on tradeoffs between density and efficiency and could generate negative effects such as the inability to balance supply and demand, high costs of living, concentrated pollution, vulnerability to disaster shocks, and exorbitant environmental impact (Rérat 2012; Westerink et al. 2013). Further, debates on which spatial forms-decentric, centric, or some hybridmeet the challenges of escalating urbanization trends and population growth adds complexity to determining whether the compact city is a sustainable urban model (Kloosterman and Musterd 2001). The divergent effects of the COVID-19 pandemic on different metropolitan cities offer an opportunity to address these challenges and assess the sustainability of the compact city model more carefully.

This study observes the effects of COVID-19 in two notable compact cities, Seoul, South Korea and New York City, USA. Both cities have compact city characteristics, such as high population density, diverse land use mix, and advanced transit system, but have experienced drastically different trends of COVID-19 transmission and response. Using these cases, the paper examines the viability of the compact city model in the face of shock events and investigates the link between density and diseases within the urban planning framework. 
In detail, this study contextualizes the COVID-19 outbreak in relation to (1) major outbreak events and government interventions and (2) the built environment and sociodemographic characteristics of urban cities. Further, to link how this is evinced in urban cities, we take a closer look at subway ridership as a representative measure linking urban compact form and mobility. Specifically, the study first analyzes the impact of government interventions on subway ridership decline after the COVID-19 outbreak. Second, it assesses how subway ridership changed before and after COVID-19. Third, it examines the association between subway ridership decline and factors related to the built environment and demographic populations. Ultimately, this study will identify factors that are closely related to COVID-19 outbreaks in highly dense cities and assess whether the compact city model is sustainable in the post-COVID-19 era.

\section{Literature review}

In the past few decades, high land and housing prices causing outward expansion of residential areas led urban development patterns to reflect characteristics of sprawl. Sprawling cities are associated with attributes such as low-density residential housing, automobile dependency, and outward expansion of urban areas (Atkinson and Oleson 1996; Johnson 2001; Dieleman and Wegener 2004; Hamidi and Ewing 2014). The negative effects of urban sprawls have been studied widely. The horizontal, and at times unplanned, expansion of road networks cause longer commute times, automobile-dependent travel exacerbate air pollution, and low-density development constrain access to public infrastructure and services (Nilles 1991; Brueckner 2000; Holcombe and Williams 2010; Nechyba and Walsh 2004; Deng and Huang 2004). Such effects construe cities' management capacity and place greater burdens on environmental, economic, and social costs draining local resources (Ciscel 2001; Carruthers and Ulfarsson 2003; Hortas-Rico and Solé-Ollé 2010). In the context of unforeseen disasters, additional costs to mitigate and respond to risks facing widely dispersed populations become unscalable (Mileti 1999; Barnes et al. 2001; Hall and Ashley 2008; Frumkin et al. 2004).

To negate the inefficiency of sprawl, the compact city model has been advocated as the paradigm for sustainable urban form. Many studies suggest that compact cities could be more environmentally, economically, and socially sustainable by intensifying urban development and activities that lead to reduced amount of travel, shorter commute time, lower car dependency, limited consumption of infrastructure materials, pollution mitigation, minimal loss of green spaces, improved diversity for choice of work and social contracts, and improved access to services and social interactions (Burton 2002; Jabareen 2006; Hofstad 2012; Bibri et al. 2020). Characteristics of the compact city, though loosely defined in literature, runs nearly parallel with the core principles of sustainable urbanism, which seeks to promote long-term resilience and viability of cities through reducing material use, energy use, and pollution emission while promoting social well-being. As such, research and policy that promote compact city forms, such as high density, mixed land use, sustainable transport, and greening have become prevalent. 
However, empirical application and examination of compact cities evince the approach's shortfalls in achieving the multiple dimensions of sustainability. For instance, the close proximity of transport facilities, residential areas, and commercial centers generate noise pollution that may negatively affect neighborhood health outcomes (De Roo 2000), while density itself could induce lower neighborhood satisfaction and quality of public facilities (Bramley and Power 2009; Dempsey et al. 2012) that risks social quality of life. Additionally, some empirical findings suggest that the potential environmental benefits of compact cities, most notably reduced transport energy use and related greenhouse gas emissions from reduced travel, are overestimated and results vary from case to case (Breheny 1995, 1997). Layered with issues of disparity that are accentuated in compact and dense environments, such as unfavorable living conditions and lack of access to green space and social services for low-income or other minority groups, the urban form and its design requires a more complex and nuanced understanding that can balance the priorities of environmentally, economically, and socially sustainable development.

Considering such nuances of sustainable development and urban spatial forms, several studies have underscored polycentric development as the key to resolving the issues of compactness and density. Though polycentricity is loosely defined in literature (Burger and Meijers 2012; Veneri and Burgalassi 2012), urban spatial structures are characterized as mono- or polycentric based on the number of urban centers and subcenters, which are defined and measured by the number of employers, population and employment density, and more (McDonald 1987; Giuliano and Small 1991; Riguelle et al. 2007). In contrast to urban sprawls and compact cities, empirical evaluations of polycentric development demonstrate its association with reduced commute time (Gordon et al. 1989), lower automobile dependency and increased use of public transit (Park et al. 2020; Choi et al. 2020), and improvement in access to public infrastructure and facilities (Decoville and Klein 2020). Further, polycentric structure allows efficient concentration of human capital and other resources in multiple locations within dense urban boundaries, which not only improves efficient allocation of resources but also strengthens resiliency of urban systems by dispersing the impact of potential threats (Sharifi 2019). As such, polycentric development could simultaneously preserve the benefits of and ameliorate the deficiency of compactness.

In addition to polycentric development, transit-oriented development has received much academic and policy attention as a means to achieve sustainable urban development. Studies that identify determinants for increased public transit use have centered on built environment features (Kuby et al. 2004; Chen et al. 2009; Gutiérrez et al. 2011; Li et al. 2020b), and many highlight mixed land use and transit-oriented development as key factors (Sung and Oh 2011; Choi et al. 2012; Lee et al. 2013). However, disruptions in public transit usage caused by COVID-19 have highlighted the vulnerability of transit-oriented development. Many compact cities have relied on transit-oriented development as a solution to alleviate problems that arise from high density, decrees to restrict the use of public transit systems during the pandemic undermined the very feature that sustains the compact urban form. Several studies have utilized these cases as an opportunity to analyze the linkage between density and disease transmission, but arrived at varied conclusions. For instance, 
Bhadra et al. (2021) identified a link between population density and COVID-19, but Hamidi et al. (2020) emphasized the link between regional connectivity and COVID-19 transmission, instead of density. Other studies suggested that employment density may be a more significant factor than population density, while studies like Ribeiro et al.'s (2020) discovered varying outbreak patterns between small and large cities. As such, the inconsistent results from existing literature highlight the need for further research on density and disease transmission.

In addition to density, urban mobility is commonly identified as a major factor related to disease transmission. During the COVID-19 pandemic, several metropolitan cities implemented varying versions of mobility restrictions, including restrictions on public transit use. Based in NYC, studies on the relationship between individuals' mobility and COVID-19 outbreak suggested that individuals' use of public transportation was related to the increase in COVID-19 cases (Harris 2020; Glaeser et al. 2020). Other studies revealed that individuals' risk perception towards COVID-19, regardless of government interventions, led to travel-related behavioral change (Bhaduri et al. 2020; Kim et al. 2021). In connection with Hamidi et al.'s results (2020), these studies suggested that traveling by public transit in highly dense cities led to overcrowding in confined spaces, which increased individuals' exposure to COVID-19 infection. However, regardless of government interventions and risk perception towards COVID-19, people continued to move within and across cities pending their trip purposes, like shopping (Abdullah et al. 2020; Shamshiripour et al. 2020), and their capacity to travel via non-public transportation modes (Bucsky 2020; Teixeira and Lopes 2020; Abdullah et al. 2021). Conclusively, public transit use is consistently highlighted as a major factor associated with disease transmission.

Current literature on disease transmission, density, and mobility highlights the need for a comprehensive urban planning approach for building sustainable and resilient cities against shocks like COVID-19. Existing literature on the effects of mobility restrictions on COVID-19 transmission (Huang et al. 2020; Park 2020; Pawar et al. 2020) and regional clustering based on transit ridership (Chen et al. 2009; Kim et al. 2017) provide a partial picture of planning solutions to risks. Thus, a holistic analysis of public transit use, COVID-19 outbreak, and government interventions could contribute to developing a long-term strategy against epidemiological shocks. To fill this gap, this study analyzes the impact of COVID-19 restrictions on subway ridership and assesses the association between subway ridership and station area built environment and socioeconomic factors.

\section{Data and methods}

\subsection{Research scope}

Debates over the compact city form and the contentious factors of disease transmission, density, and mobility converge in NYC and Seoul, South Korea. Both cities represent high-density urban environments with compact spatial forms that serve as regional centers for development and activity. NYC is the densest city in the USA, 
with over 10,400 people per square kilometer (27,000 people per square mile) as of 2010 (U.S. Census Bureau 2021). Seoul also has the highest density in Korea with over 15,800 people per square kilometer as of 2020 (Statistics Korea 2021). Also, both cities have multifunctional land use mix to support diverse economic industries such as banking, finance, technology, manufacturing, media, and more. The mass transit system of the two cities allow residents of peripheral regions in their metropolitan area to take advantage of these economic activities. Composed of various travel modes, including subways, buses, bikes, personal vehicles, and more, Seoul and NYC's public transit systems support about 1.3 million in-flow commuters as of 2020 and about 973,000 in-flow commuters as of 2017, respectively, on a daily basis (Seoul Open Data Plaza 2021; NYC Department of Planning 2019).

Despite their shared compact spatial forms, NYC and Seoul underwent vastly different experiences in the face of COVID-19. By the spring of 2020, NYC became the epicenter of COVID-19 outbreak in the USA. State-level restrictions on nonessential businesses, schools, child care centers, entertainment and recreation facilities, restaurants, and other city amenities took several months to a year to be lifted (Office of New York City Comptroller 2021). As mentioned above, these interventions negatively affected the real estate market and other sectors, especially on nonessential jobs that were halted due to mobility restrictions. In contrast, Seoul's witnessed fewer cases of COVID-19 at the onset of the pandemic and implemented social distancing guidelines that impacted social and economic activity at a relatively minimal scale than that of NYC. The two cities, similar in spatial form but different in response to the pandemic disruptions, became the focus of many studies examining disease transmission, density, and mobility as detailed above in this section.

\subsection{Data}

To observe change in mobility following COVID-19 outbreaks, this study observed subway ridership as the key variable using 2019 data subway data from Seoul. To contextualize findings from Seoul with other notable compact cities, we also considered NYC with scaled-out compact city characteristics compares to Seoul. Specifically, Seoul's subway turnstile data were collected from Seoul Open Data Plaza ${ }^{1}$ and NYC's from the Metropolitan Transportation Authority (MTA) ${ }^{2}$. Both cities' turnstile data included entry and exit data for all stations, totaling 296 for Seoul and 421 for NYC. Though studies on subway ridership typically utilize hourly turnstile data, this study utilized station-level daily turnstile data corroborate with the longer time period considered in the study's scope.

COVID-19 cases data for the corresponding time period were collected from Korea Disease Control and Prevention Agency $(\mathrm{KDCA})^{3}$ and Seoul National

\footnotetext{
1 https://data.seoul.go.kr/dataList/OA-12914/S/1/datasetView.do.

2 http://web.mta.info/developers/turnstile.html.

3 http://www.kdca.go.kr/npt/biz/npp/portal/nppIssueIcdMain.do.
} 
University Asia Center-Asia Regional Information Center (SNUAC ARIC) ${ }^{4}$ for Seoul, and from Johns Hopkins Coronavirus Resource Center ${ }^{5}$ and NYC Department of Health and Mental Hygiene ${ }^{6}$ for New York City. Information about national and city-level interventions in Korea and Seoul was collected from KDCA and Korea's Ministry of Health and Welfare, ${ }^{7}$ and corresponding information about New York State and NYC were obtained from the official website of the New York State Governor. ${ }^{8}$ For both cities, additional news media sources were referenced to track detailed updates about government interventions.

Following the subway ridership dynamic analysis, the study conducted multiple regression analyses to identify built environment and sociodemographic factors associated with the change in subway ridership during the COVID-19 pandemic. The variables representing the built environment reflect the 3D's-density, diversity, and design - that were introduced by Cervero and Kockelman (1997). First, representing density or compactness around subway stations, activity density (Activitydens) was computed by dividing the sum of residential and employment populations by the corresponding land area as was done in previous studies (Ewing et al. 2015; Kim et al. 2018; Hamidi et al. 2020). Though the study could have used population density, typically including residential population only, it uses activity density that incorporates employment population to reflect work-related contact that may influence COVID-19 spread differently. Second, the land use mix index (Landusemix) was used as a measure for diversity, which was computed with the equation suggested by Bhat and Guo (2007). Mixed land use, typically perceived as a solution to problems arising in highly dense cities such as housing shortage, traffic, uneven development, and pollution, is a key feature of compact cities. However, its role in sustaining the compact city form is jeopardized in the context of the pandemic, when urban connectivity could serve as a vulnerability. Third, station attribute variables like the number of bus stops within $500 \mathrm{~m}$ radius of subway station (Busstop) was used to represent design. Though design variables typically entail road density and number of intersections, Busstop was used as a measure of intermodal connection and continuity (Sung and Oh 2011; Cao et al. 2020). Further, stations where transfer to a different subway line were classified with a dummy variable (Transfer), which contextualizes attributes related to stations.

Among sociodemographic factors, the ratio of jobs in accommodation and food services industry to total jobs (Pempl_accfood) was selected to observe the impact of social distancing guidelines imposed during the pandemic. Technically, this variable is the ratio of jobs in the accommodation and food services industry to total jobs in the area near subway stations. Unlike COVID-19 guidelines that strictly restricted movement such as shutdown measure that were temporarily imposed

\footnotetext{
4 https://sites.google.com/view/snuaric/covid-19/covid-19-data.

5 https://data.humdata.org/dataset/novel-coronavirus-2019-ncov-cases.

6 https://data.cityofnewyork.us/Health/COVID-19-Daily-Counts-of-Cases-Hospitalizations-an/rc75$\mathrm{m} 7 \mathrm{u} 3$.

7 http://ncov.mohw.go.kr/tcmBoardList.do?brdId=3.

8 https://www.governor.ny.gov/news.
} 
in NYC, Seoul's COVID-19 guidelines partially restricted movements because of its reliance on voluntary participation. Nonetheless, this variable was selected to observe the role of indoor dining and operating hour restrictions on food servicers to prevent overcrowding during the pandemic. Other variables related to land use (Pindustry_manuf and Popensp_rec) and sociodemographic characteristics (P20to64 and P65over) were included as control variables.

Data for land use-related variables were collected from the Land Use Map, curated by the Korea National Spatial Data Infrastructure Portal, ${ }^{9}$ and data related to station attributes were collected from Seoul Open Data Plaza. Data for sociodemographic variables at the jipgyegu level, the smallest statistical area level surveyed by the Korean government, were collected from KOSIS Statistical Geographic Information Service. ${ }^{10}$ ESRI's ArcGIS Pro was used to extract additional geographic information data.

For the multiple regression analysis of factors affecting subway ridership, the independent variables pertain to land area, facilities, and jipgyegu within a $500 \mathrm{~m}$-radius of each subway station. The $500 \mathrm{~m}$ radius distance is designated by the Korean Urban Planning Law as the primary catchment area for subway stations. Other studies on subway ridership and station level based in Seoul and Tokyo also used $500 \mathrm{~m}$ as the subway station catchment area (Sung and Oh 2011; Choi et al. 2012; Kim et al. 2017; Cao et al. 2020). Detailed description and descriptive statistics of the variables used in the regression analysis are listed in Table 1.

\subsection{Research method}

\subsubsection{Ridership dynamics}

First, to observe the dynamics of COVID-19-specific events, government interventions, and subway ridership, we represented the change in subway ridership of the cities in line graph form and depicted COVID-19 cases and deaths count in bar graph form. Additionally, specific events, like the first COVID-19 death, mass outbreak cases, peak COVID-19 cases, and notable government intervention periods were marked on the diagram to provide more context behind the ridership change.

\subsubsection{Time-series clustering}

To measure the similarity of change in the number of passengers over time at different stations, this study used Dynamic Time Warping (DTW), from which K-medoids clustering was performed to identify stations with similar changes in the number of passengers.

The K-medoids algorithm, also known as Partitioning Around Medoids, is a clustering methodology proposed by Kaufman and Rousseeuw (2009). K-medoids

\footnotetext{
9 http://www.nsdi.go.kr/lxportal/?menuno=2679.

$10 \mathrm{https}: / /$ sgis.kostat.go.kr/jsp/english/index.jsp.
} 


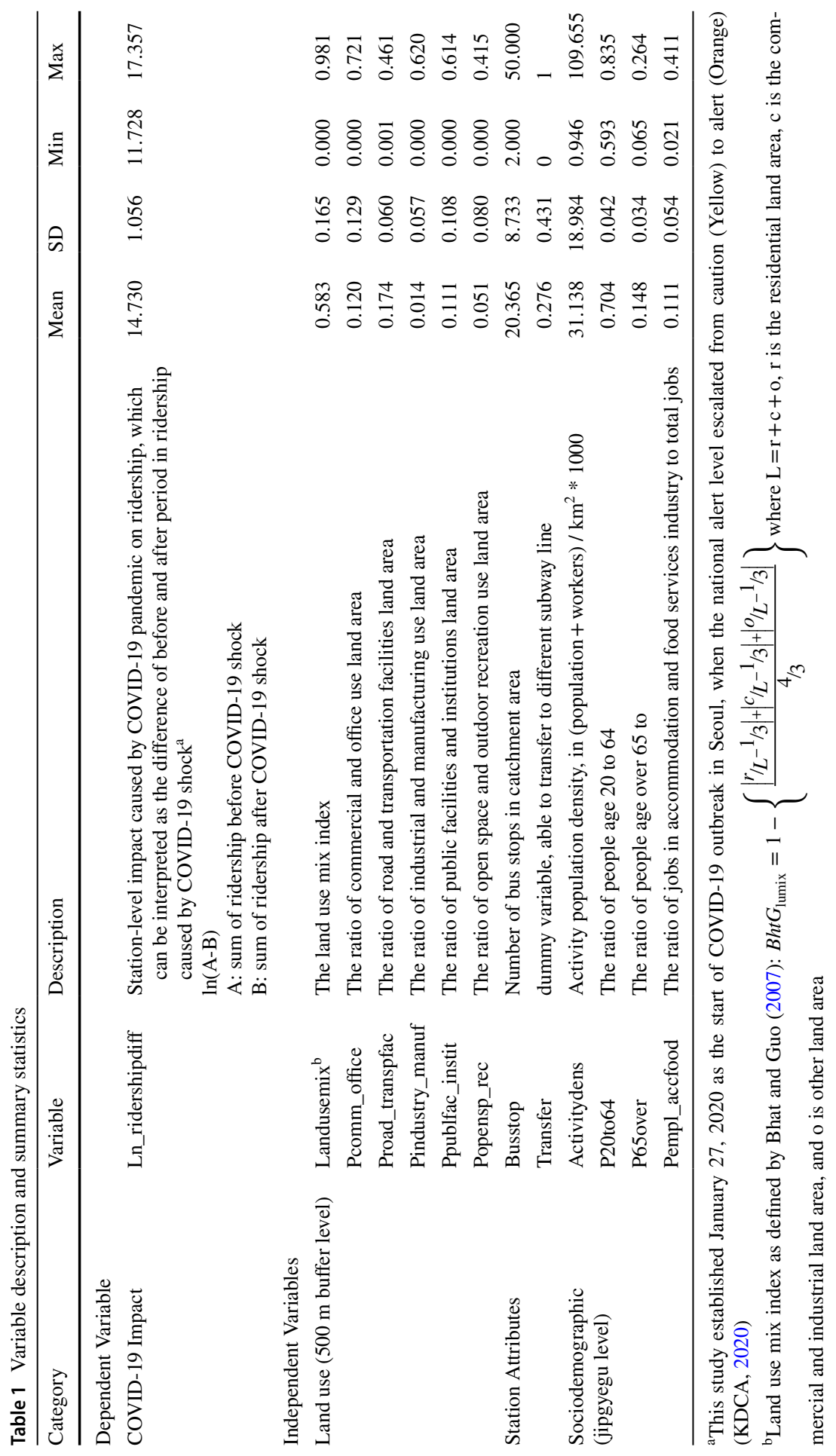


algorithm is a representative object-based technique algorithm that forms $\mathrm{K}$ number of clusters based on the distance between medoids point and its neighboring data. Similar clustering algorithms include the K-means algorithm proposed by MacQueen (1967). Similar to the K-medoids algorithm, the K-means algorithm provides $\mathrm{K}$ cluster results; however, it has several disadvantages. One, K-means algorithm could generate varying results each time due to random designation of the cluster center. Two, it could exclude points with anomalously short distances from other randomly designated center points. Last, it is highly sensitive to outliers due to dependence on the mean during the clustering process.

Addressing the disadvantages of the K-means algorithm, the K-medoids algorithm first selects $\mathrm{K}$ number of medoids, then proceeds with the clustering process. In this process, each medoid represents an object nearest to the center point instead of a value; therefore, medoids are newly selected in each clustering process until the optimal clusters are formed. The detailed procedure as proposed by Han et al. (2011) is as follows:

Step 1:Determine K, the number of clusters, and the medoids of each cluster

Step 2:Form a new cluster by assigning a nearby data point to a cluster centered on the representative object

Step 3:Specify a new representative object that minimizes the distance, or cost, from the new cluster

Step 4:Repeat the process 2-3 times until no data are left to be clustered

This study determined $\mathrm{K}=6$ based on the number of elbow points derived from the within-groups sum of squares. The study proceeded with time-clustering method with the cost based on dynamic time warping (DTW) algorithm. DTW is an algorithm proposed by Bellman and Kalaba (1959) and is used to check the flow of multiple time data and measure their similarity. It is widely used in voice recognition (Amin and Mahmood 2008), online signature identification (Sharma and Sundaram 2017), and gesture recognition (Celebi et al. 2013). While Euclidean distance-based similarity measurements are sensitive to changes in time axes and data based on 1-to-1 matching between the two points, similarity measurements derived from DTW algorithm are not affected by changes in the distance between data points and are relatively robust by considering shifts among data (Keogh and Pazzani 1999; Wang et al. 2018).

In the context of this study, the DTW used as the basis of the K-medoids clustering conducted in this study could be understood as follows. Assume there exists two time vectors $(\tilde{\mathbf{a}}, \mathbf{b})$ and the similarity in their time flow is to be estimated. First, the Euclidian distance matrix of the distance between each vector's elements can be constructed with i rows and j columns as shown in Eq. 1.

$$
\begin{aligned}
& \tilde{\mathbf{a}}=\mathrm{a}_{1}, \mathrm{a}_{2}, \mathrm{a}_{3}, \mathrm{a}_{4}, \cdots, \mathrm{a}_{\mathrm{s}} \\
& \tilde{\mathbf{b}}=\mathrm{b}_{1}, \mathrm{~b}_{2}, \mathrm{~b}_{3}, \mathrm{~b}_{4}, \cdots, \mathrm{b}_{\mathrm{t}} \\
& D_{i j}=\sqrt{\left(\mathrm{a}_{\mathrm{i}}-\mathrm{b}_{\mathrm{j}}\right)^{2}}(1 \leq \mathrm{i} \leq \mathrm{s}, 1 \leq \mathrm{j} \leq \mathrm{t})
\end{aligned}
$$




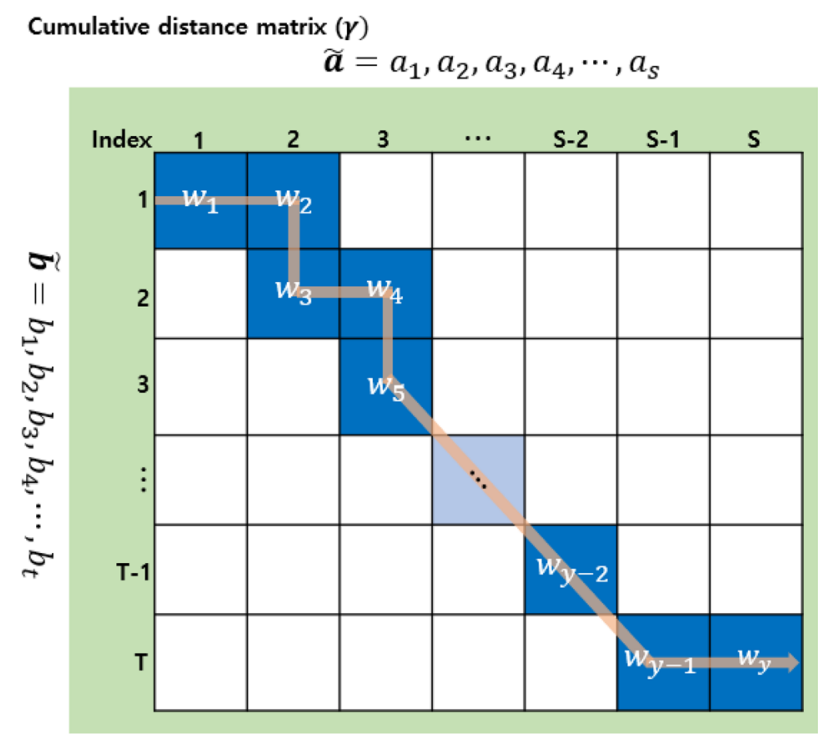

Fig. 1 Finding Warping path based on $\operatorname{DTW}(\tilde{a}, \tilde{b})$

Then, the DTW distance matrix can be constructed using dynamic programming, which accounts for the minimum values of the Euclidian distance matrix and the adjacent matrices' elements. The elements of the first row and first column of the DTW distance matrix correspond to the first row and first column elements of the Euclidian distance matrix, and the $\mathrm{i}$-th and $\mathrm{j}$-th element could be expressed as Eq. 2.

$$
\gamma(i, j)=D_{i, j}+\min \{\gamma(i-1, j), \gamma(i, j-1), \gamma(i-1, j-1)\}
$$

The optimal warping path (Fig. 1) could also be derived by minimizing the warping cost equation (Eq. 3) within the matrix. In detail, the warping path is a vector with elements that minimize the warping $\operatorname{cost}(=D T W(\tilde{\boldsymbol{a}}, \tilde{\boldsymbol{b}}))$ in the cumulative distance matrix, and shows the similarity between the two vectors' elements that are matched based on the index of the corresponding cumulative distance matrix.

$$
\begin{aligned}
& \tilde{\boldsymbol{W}}=w_{1}, w_{2}, w_{3}, w_{4}, \cdots, w_{y}(\max (s, t) \leq y \leq s+t+1) \\
& \operatorname{DTW}(\tilde{\boldsymbol{a}}, \tilde{\boldsymbol{b}})=\operatorname{Min}\left\{\sum_{x=1}^{y} w_{x}\right\}
\end{aligned}
$$

\subsubsection{Multiple regression}

The multiple regression analysis will use ordinary least squares (OLS) estimation to assess the association between subway ridership after COVID-19 and factors related to land use and sociodemographic characteristics. 


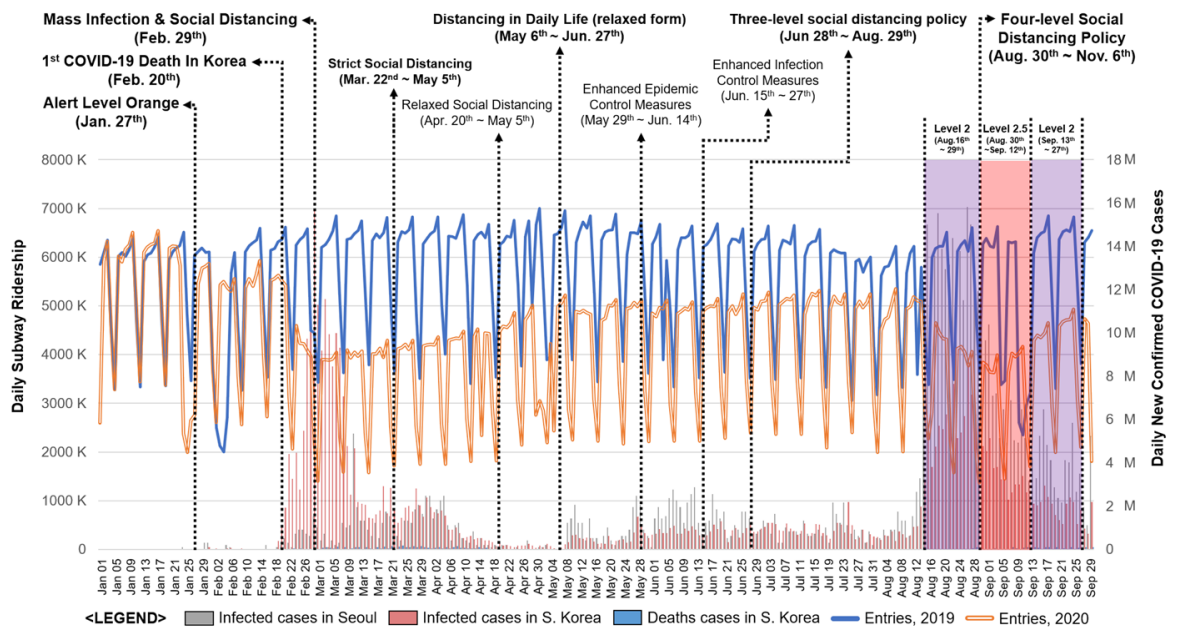

Fig. 2 Timeline of COVID-19 \& subway ridership dynamics in Seoul. Source Seoul Open Data Plaza (Subway Ridership), KCDC (Interventions \& COVID-19), SNUAC ARIC (COVID-19), Ministry of Health and Welfare (Interventions)

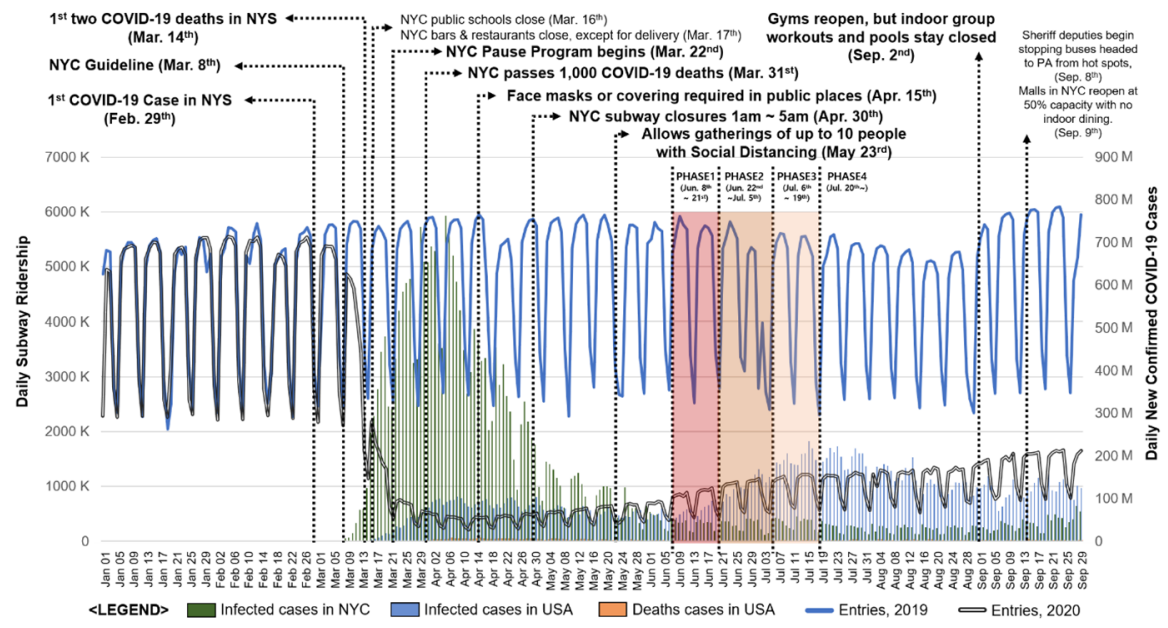

Fig. 3 Timeline of COVID-19 and subway ridership dynamics in New York City. Source MTA (Subway Ridership), NYC Open Data (COVD-19), Johns Hopkins Bloomberg School of Public Health (COVID19), Official Website of Governor of NYS (Interventions)

\section{Results and discussion}

\subsection{Subway ridership dynamics}

The dynamics of COVID-19 outbreak, intervention measures, and subway ridership are demonstrated in Figs. 2 and 3. In detail, ridership is equivalent to the sum of all 
daily subway entries in each city and represents individuals' behavioral choice in response to COVID-19.

In Seoul, ridership slightly declined after the Orange-alert level was alarmed on January 27th and then further declined after the first COVID-19-induced death occurred on February 20th. This drastic decline continued through mass outbreaks in Daegu and Kyung-Buk provinces, where cases reached peak points on February 29th. Thereafter, ridership began to recover until it flattened starting the second week of May. However, due to a seasonal declining pattern also shown in 2019, the ridership patterns appear to reflect previous counts and maintain an existing trend. Then, as cases per million people began to surpass that of the February 29th peak in mid-August, social distancing guidelines were raised to Level 2 starting August 16th. During this period, ridership began to decline like that of late-February, but the rate of decline was less severe. However, ridership rebounded in early-September when the city heightened the social distancing guidelines to Level 2.5 after outbreak that started mid-August persisted. After the rebound, ridership began to recover through late September.

Seoul's dynamics trend indicates that subway ridership acutely dropped after specific events and surged after interventions were implemented. Also, ridership recovery in both late-February and early-September occurred regardless of the location of the outbreaks while the rate of recovery was faster in the latter period than the former. These observations suggest that national outbreak events affect Seoul's ridership, and the magnitude of that impact could be influenced by the timing of the outbreak. Conclusively, individual behavior could be more affected by the outbreak timing than by the location of the outbreaks.

In NYC, similar to that of Seoul, subway ridership pattern between 2019 and 2020 is similar until the first COVID-19 case was confirmed on February 29th. Thereafter, ridership began to decline and declined further starting March 8th, when NYC began to issue mitigation interventions. Ridership further declined after the state announced the "New York on PAUSE" (PAUSE) order, but began to bounce back starting April 15th, when face masks or coverings were mandated in public places. As the recovery trend continued, the rollout of Reopening Plan Phase One on June 8th accentuated the ridership increase. This incline continued through Phase Two and began to stagnate after Phase Three was introduced on July 5th. However, like Seoul's ridership pattern, NYC's appears to reflect previous year's trend considering seasonal factors. A minutely inclining pattern started in early September, when COVID-19 cases began to remain under 250 people per day, movement and indoor activity restrictions were eased, schools and universities gradually reopened, and other reopening guidelines took place.

NYC's dynamics trend indicates that NYC's subway ridership was largely affected by the outbreak in early stage of the pandemic. Generally, ridership appeared to decline after restriction measures were introduced or intensified while it increased after public health guidelines, such as face mask or covering mandates, and reopening plan phases were implemented. A more microsopic observation of NYC's ridership reveals that, despite a national increase in COVID-19 cases, NYC's subway ridership gradually recovers after the sharp decline in the initial stage of the pandemic. This observation suggests that NYC's ridership is significantly affected 
by national outbreak events, but by government mitigation strategies. As a result, NYC residents' behavioral response to COVID-19 is more affected by government interventions than by the outbreak pattern.

Comparing the dynamics of both cities, NYC's ridership decreases more significantly than Seoul's at the onset of the pandemic, mid-February in Seoul and earlyMarch in NYC. The difference in these trends can be attributed to the difference in their disease response strategy per the cities' differing scale and gravity of the pandemic's impact. Whereas Seoul facilitated multiple softer guidelines like social distancing, quarantine, and contact tracing, NYC enforced more stringent rules through PAUSE. PAUSE required all non-essential businesses to close, canceled or postponed non-essential meetings, and restricted individuals' mobility. In contrast, Seoul's strategy centered on encouraging social distancing and wearing of face masks, regulating indoor dining, and limiting group gatherings but not entirely restricting individuals' movements.

Other than the intervention level, factors such as personal perception of risk, ability to work remotely, and the feasibility of travel mode shift could be essential factors for the different ridership pattern in Seoul and NYC. Although the two cities' subway modal share is similar-NYC's 38.5\% (U.S. Census Bureau 2020) and Seoul's 40.7\% (Seoul Metropolitan Government 2020) - their paths for subway ridership recovery following the initial COVID-19 outbreak diverge. In NYC, where ridership recovery occurred at a slower pace, travel through personal vehicle recovered the earliest (Ye et al. 2021; Kamga et al. 2020). Further, when restrictions of subway use were imposed, use of personal vehicles and bike share systems increased (Bian et al. 2021), while use of taxis increased in areas with higher low-income populations and dependency on public transit (Manley et al. 2021). Such travel behaviors and modal shift among New York City residents reveal the various factors affecting shift from subways to alternative travel options during COVID-19.

The two cases suggest that government interventions that restrict individuals' mobility cause COVID-19 cases to decline. In response to the mass outbreak earlier in the pandemic, NYC shut down the city with austere movement restrictions and gradually reopened the city as the disease outbreak stabilized and eventually declined. In Seoul, however, social distancing and other mitigation strategies were administered but individual mobility was not severely restricted to the level of a shutdowns. As such, even after the mass outbreak in Daegu and Kyung-Buk that led to the pre-second wave period near June 22nd, subway ridership in Seoul did not significantly reduce and continued through the second wave that centered on Seoul starting mid-August.

The differing approaches of NYC and Seoul reveal the limits of shutdown and social distancing measures on mitigating the effects of COVID-19. For instance, although NYC's shutdown measures effectively curbed the surge of COVID19 cases, they may have left negative socioeconomic effects on the livelihood of New Yorkers, especially for low-income families and people of color. For instance, almost half of all NYC workers lost employment income at the height of the pandemic (Collyer et al. 2020); however, differences in essential worker status contributed to deepening racial and socioeconomic disparities in COVID-19 transmission. Black and Hispanic workers were more likely to be required to work on-site (Collyer 


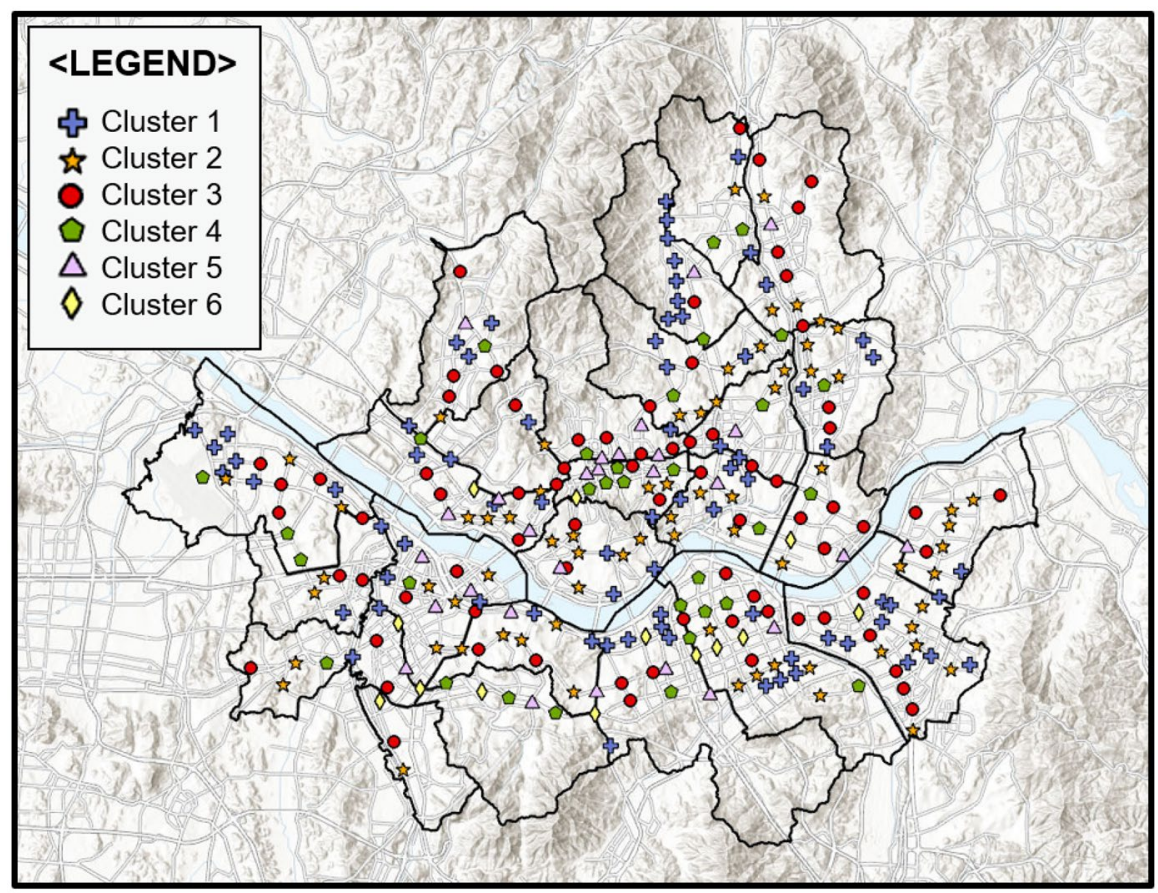

Fig. 4 Spatial distribution of clusters

et al. 2020), facing increased risk of transmission in the workplace and via public transit (Dubay et al. 2020; Hawkins 2020). Simultaneously, low-wage workers were less likely to have access to paid leave to stay home even if they had become sick or were exposed to COVID-19 (US Bureau of Labor Statistics 2021), further risking their economic and physical well-being. Similarly, Seoul's social distancing measures helped slow the spread of COVID-19 at an early stage; however, its long-term effectiveness was disproved in its compact city form. This result implies that different countries' COVID-19 response strategies could yield place-blind and uniform results, and confirms that OECD's (2020) recommendation to apply both placebased and people-based approaches to control the pandemic could be effective.

\subsection{Time-series clustering of Seoul subway stations}

Following the dynamics analysis, time-series clustering of the 296 subway stations in Seoul was conducted to formulate six clusters based on time-series ridership pattern (Table 2). Cluster one had 75 stations, cluster two had 72 stations, cluster three had 76 stations, cluster four had 32 stations, cluster five had 28 stations and cluster six had 13 stations (Fig. 4).

In all stations, subway ridership declined following the first confirmed case and outbreak of COVID-19, which is January 24, 2020, for Seoul and January 20, 2020, 
Table 2 Results of station classification

\begin{tabular}{llc}
\hline Cluster & Representative stations & N \\
\hline Cluster 1 & $\begin{array}{l}\text { Medoid Station: Saetgang } \\
\text { April 19th National Cemetery, Gaori, Gajwa, Gaerong, Gaepo-dong, Gaehwa, Gae- } \\
\text { hwasan, National Police Hospital, Airport Market, Guryong, Gubanpo, Gusan, Guil, }\end{array}$ \\
& Namtaeryeong, Nodeul, Noksapyeong, Nokcheon, Daemosan, Dorimcheon, Dobong, \\
& Dokbawi, Dunchon Oryun, Magok, Majang, Macheon, Mongchontoseong, Muakjae, \\
& Banpo, Banghwa, Beotigogae, Bukhansan Bogungmun, Bukhansan Ui, Sapyeong, \\
& Samseong Jungang, Samyang, Samyang Sageori, Samjeon, Sangwolgok, Saetgang, \\
& Sogang Univ., Seobinggo, Seokchon Gobun, Seonyudo, Solbat Park, Solsaem, Song- \\
& panaru, Susaek, Singeumho, Sinnae, Sindap, Sinmokdong, Sinbapo, Sinbanghwa, \\
& Aeogae, Yangwon, Yangcheon-gu Office, Yeokchon, Yongdap, Yongdu, Yongmasan, \\
& Wolgye, World Cup Stadium, Eungbong, Jamwon, Jeongneung, Jungnang, VHS Medi- \\
& cal Center, Jeungmi, Changsin, Hangnyeoul, Hannam, Hanseong Baekje, Hwagye, \\
& Dongjak, Yangpyeong
\end{tabular}

Cluster 2 Medoid Station: Ogeum

Gangdong-gu Office, Geoyeo, Godeok station, Korea Univ., Gongneung, Kwangwoon Univ., Gwangheungchang, Gubeundari, Geumcheon-gu Office, Geumho, Gil-dong, Namseong, Namyeong, Daecheong, Daechi, Daeheung, Dongnimmun, Dolgoji, Dongguk Univ., Dunchon-dong, Deungchon, Ttukseom Park, Madeul, Mangu, Maebong, Meokgol, Myeongil, Bangi, Banghak, Boramae, Bonghwasan, Sangdo, Sangsu, Seoulforest, Songjeong, Songpa, Sinimun, Sinjeong, Sinjeongnegeori, Sinpung, Ahyeon, Anam, Yangcheon Hyanggyo, Eonju, Yeouinaru, Yeongdeungpo Market, Oryu-dong, Hankuk Univ. of Foreign Studies, Wolgok, Itaewon, Ilwon, Jangseungbaegi, Junggok, Junghwa, Jeungsan, Cheonwang, Hangangjin, Hanyang Univ., Haengdang, Hwarangdae, Heukseok, Dogok, Bomun, Bokjeong, Samgakji, Singil, Ogeum, Oksu, Olympic Park, Ichon, Cheonggu, Hyochang Park

Cluster 3 Medoid Station: Jangji

Gayang, Gangdong, Gyeongbokgung, Gwangnaru, Guro, Guui, Gupabal, National Assembly, Gireum, Namguro, Naebang, Nokbeon, Nonhyeon, Dapsimni, Danggogae, Daebang, Doksan, Ttukseom, Mapo, Mapo-gu Office, Mangwon, Myeonmok, Mokdong, Mullae, Munjeong, Mia, Balsan, Bangbae, Bongeunsa, Gajeong, Sanggye, Sangwansimni, Sangil-dong, Saejeol, Seodaemun, Seocho, Sookmyung Women's Univ., Soongsil Univ., Sindaebangsamgeori, Sinyongsan, Achasan, Anguk, Amsa, Apgujeong Rodeo, Children's Grand Park, Yeomchang, Omokgyo, Ujangsan, Eungam, Ewha Womans Univ., Jamsillaru, Jamsil Saenae, Jangji, Janghanpyeong, Jegidong, Jongno 5(o)-ga, Junggye, Cheongdam, Hagye, Hansung Univ., Hanti, Hongje, Garak Market, Dobongsan, Dongmyo, Magongnaru, Seokchon, Seonjeongneung, Suraksan, Sinseoldong, Yaksu, Onsu, Euljiro 4(sa)-ga, Sports Complex, Chungjeongno, Taereung

Cluster 4 Medoid Station: Nakseongdae

Gaebong, Gwanghwamun, Kkachisan, Nakseongdae, Nambu Bus Terminal, Myeongdong, Miasageori, Bongcheon, Seongsu, Sinnonheyon, Sindaebang, Sinsa, Ssangmun, Apgujeong, Hak-dong, Hwagok, Hoegi, Hoeheyon, Gangnam-gu Office, Gunja, Gimpo Int. Airport, Digital Media City, Bulgwang, Sangbong, Seokgye, Sungshin Women's Univ., Suseo, Sindang, Yeongdeungpo-gu Office, Euljiro 3(sam)-ga, Chang-dong, Chungmuro

Cluster 5 Medoid Station: Noryangjin Gangbyeon, Samseong, Seoul Nat'l Univ., Suyu, Yangjae, Yeongdeungpo, Yongsan, Euljiro 1(il)-ga, Jonggak, Hyehwa, Gongdeok, Seoul Nat'1 Univ. of Education, Noryangjin, Nowon, Dangsan, Daerim, Dongdaemun, Dongdemun History \& Culture Park, City Hall, Sinchon, Yeouido, Yeonsinnae, Wangsimni, Isu (Chongshin Univ.), Jongno 3(sam)-ga, Cheonho, Cheongnyangni, Hapjeong 
Table 2 (continued)

\begin{tabular}{llc}
\hline Cluster & Representative stations & $\mathrm{N}$ \\
\hline Cluster 6 & $\begin{array}{l}\text { Medoid Station: Sillim } \\
\text { Sillim, Sadang, Konkuk Univ., Express Bus Terminal, Jamsil, Hongik Univ., Guro Digi- } \\
\text { tal Complex, Gasan Digital Complex, Gangnam, Yeoksam, Seolleung, Seoul Station, } \\
\text { Sindorim }\end{array}$ & 13 \\
\hline
\end{tabular}

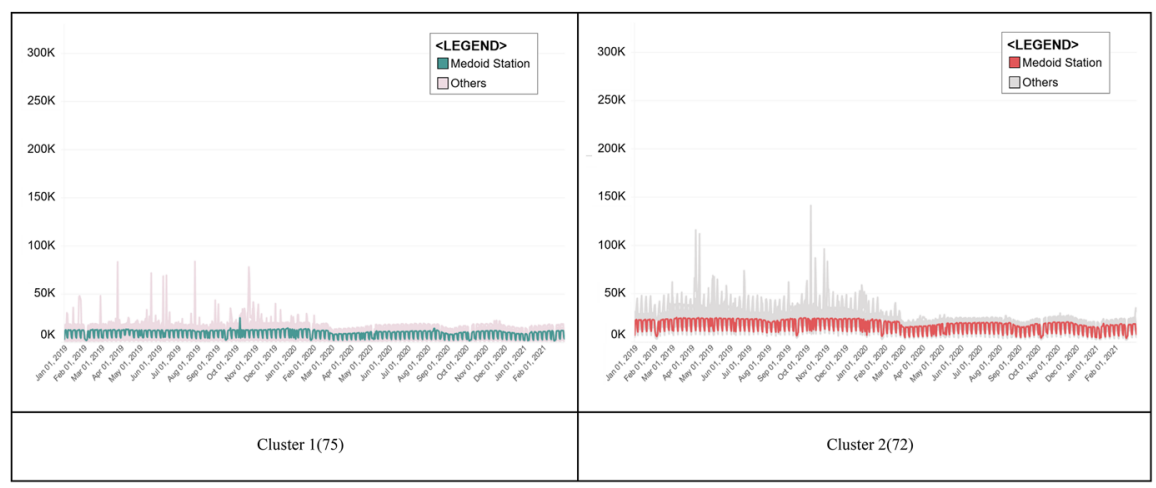
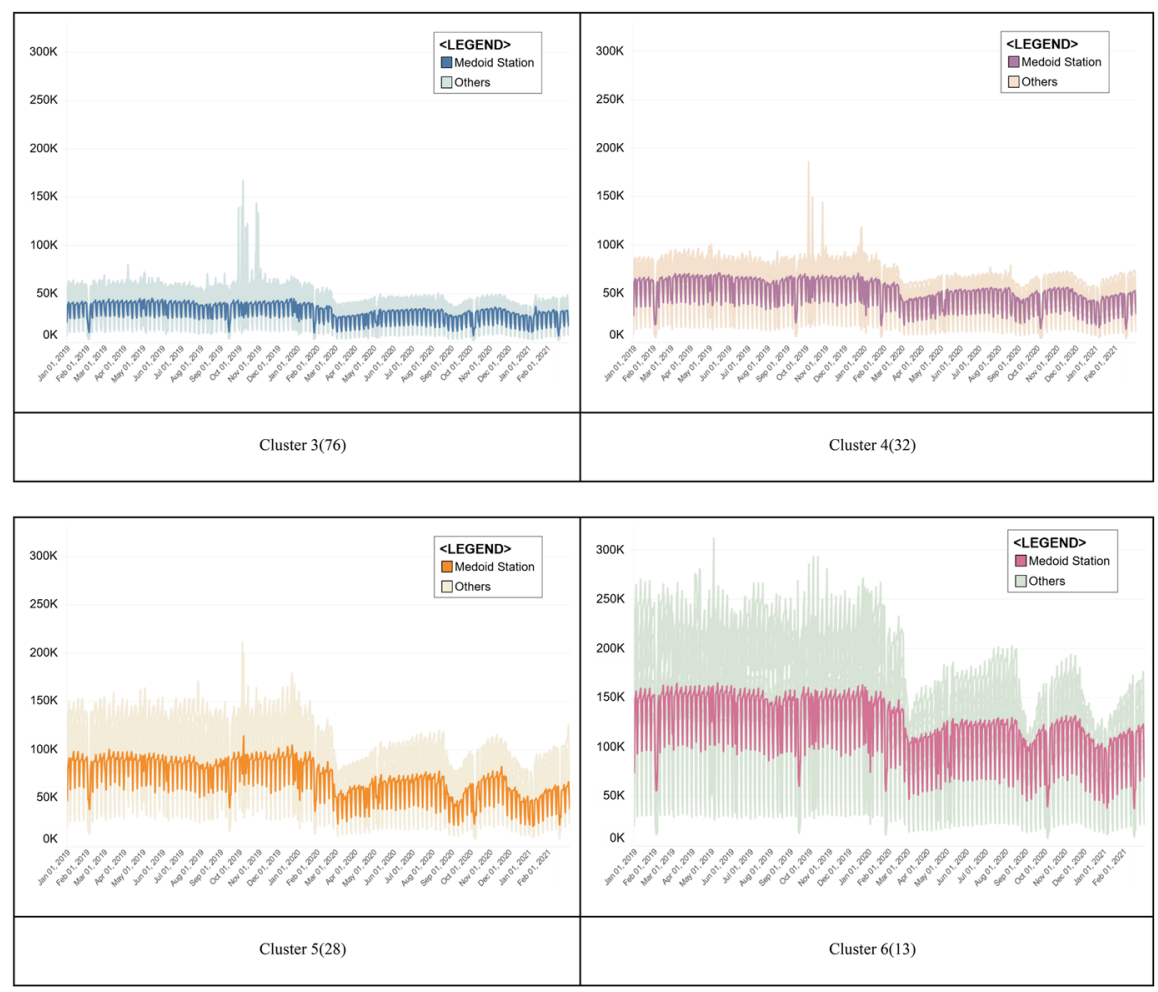

Fig. 5 Dynamics of subway ridership for cluster 1 to cluster 6 
Table 3 Subway ridership pre- and post-COVID-19 outbreak

\begin{tabular}{lll}
$\begin{array}{l}\text { Pre-COVID-19 Ridership } \\
\text { Level (A) }\end{array}$ & $\begin{array}{l}\text { Post-COVID-19 Ridership } \\
\text { Level (B) }\end{array}$ & $\begin{array}{l}\text { Difference between } \\
\text { pre- and post-COVID-19 } \\
\text { (C=A-B) }\end{array}$ \\
\hline $14,869,073$ & $10,702,957$ & $4,166,116$ \\
$3,499,624$ & $2,704,772$ & 794,852 \\
$8,084,319$ & $5,900,003$ & $2,184,316$ \\
$13,909,813$ & $10,443,788$ & $3,466,026$ \\
$22,786,860$ & $16,692,297$ & $6,094,563$ \\
$35,441,892$ & $24,293,204$ & $11,148,688$ \\
$59,846,490$ & $40,948,154$ & $18,898,336$
\end{tabular}

The number of days before and after the COVID-19 outbreak ranges between 392 and 399 with about 7 days discrepancy, but is uniform across all stations

for South Korea nationally (Fig. 5). After the decline, ridership generally increases in all stations, which signaled some resilience towards bouncing back to preCOVID-19 levels. However, stations with higher ridership counts exhibited delayed recovery to pre-COVID levels. Also, though the variance between pre- and postCOVID ridership narrows, the order of change in variance among stations does not change. As such, the overall ridership pattern appears to not have changed despite the reduction in total ridership. In particular, more frequented stations exhibited less evident changes in ridership pattern between pre- and post-COVID levels.

Comparing the difference in total subway ridership pre- and post-COVID offers a more detailed picture (Table 3 ), in which smaller $\mathrm{C}$ values signal stronger resiliency.

The clustering results reveal that subway stations with typically higher ridership level underwent larger fluctuation in ridership, and stations with lower ridership level underwent smaller fluctuation in ridership. In the context of individual behaviors related to COVID-19-related risks (Bucsky 2020; Li et al. 2020a; Shamshiripour et al. 2020; Abdullah et al. 2021; Kim et al. 2021), this result suggests a possible close association between subway ridership and travel purpose. For instance, ridership fluctuation at stations linked with non-mandatory trip purposes, like leisure, will likely be non-stationary and ridership fluctuation at stations linked with mandatory trip purposes, like commute for work, will likely be more stationary. In Seoul, ridership at stations linked with mandatory trip purposes will likely be lower since the residences of people with jobs in Seoul are distributed across the greater Seoul Metropolitan Area.

The result of the ridership-based clustering analysis suggests that the impact of COVID-19 varies across stations and reveals that the fluctuation in ridership preand post-COVID-19 varies according to the scale of ridership levels. This implication is attributed to the idea that individuals' perception of and response to COVID19 risks could be reflected by their trip purpose and personal choice of travel mode, represented as subway ridership level.

Figure 6 illustrates ridership level at each cluster's medoid station with key pandemic-related events and interventions. Cluster 6 stations have prominently 


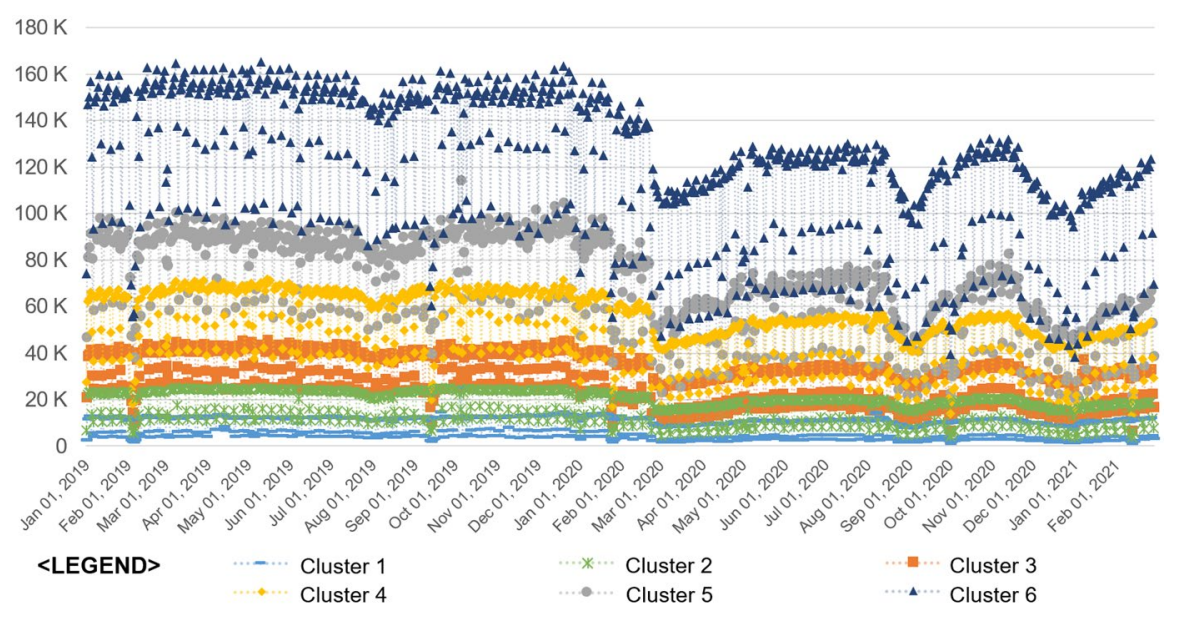

Fig. 6 Dynamics of subway ridership for cluster 1 to cluster 6 medoids in Seoul

Table 4 Descriptive statistics of ridership at medoid station of each cluster

\begin{tabular}{|c|c|c|c|c|c|c|c|}
\hline \multicolumn{4}{|c|}{ Ridership at each cluster medoid station } & \multicolumn{4}{|c|}{ Cluster mean of mean } \\
\hline Cluster & Mean & SD & Variance & Cluster $(\mathrm{N})$ & Mean & SD & Variance \\
\hline 1 & 31,853 & 8,724 & $76,110,888$ & $1(76)$ & 30,827 & 9,620 & $92,539,263$ \\
\hline 2 & 69,791 & 19,701 & $388,123,520$ & $2(28)$ & 75,614 & 23,398 & $547,476,414$ \\
\hline 3 & 51,052 & 13,931 & $194,072,874$ & $3(32)$ & 49,974 & 15,460 & $239,021,703$ \\
\hline 4 & 9,275 & 3,800 & $14,438,597$ & $4(75)$ & 7,854 & 2,314 & $5,356,784$ \\
\hline 5 & 17,461 & 5,888 & $34,666,194$ & $5(72)$ & 17,702 & 5,383 & $28,973,041$ \\
\hline 6 & 120,389 & 30,414 & $924,984,490$ & $6(13)$ & 127,588 & 39,268 & $1,541,958,214$ \\
\hline
\end{tabular}

Estimates based on descriptive statistics of daily subway ridership from January 2019 to February 2021

high and mire fluctuating ridership levels over time, which implies a more elastic nature of demand for Cluster 6 stations. This finding also suggests that Cluster 6 stations could act as disease transmission since higher ridership level alludes to greater mobility and possible overcrowding (Hamidi et al. 2020; Bhadra et al. 2021). With smaller degrees in fluctuation, Clusters 4 and 5 stations exhibit similar patterns of high and more fluctuating ridership level. In contrast, Clusters 1, 2, and 3 all display similar patterns of average ridership level with minutely different and relatively small fluctuation range. As shown in Table 4, the mean, standard deviation, and variance all increase as the Cluster numbers increase, which implies that stations with higher daily ridership counts face greater fluctuation in ridership. As such, the study finds that stations with higher ridership levels endure wider fluctuation in ridership following disease spread, implying that contagious diseases like COVID-19 leaves greater impact on stations where overcrowding occurs more frequently. 


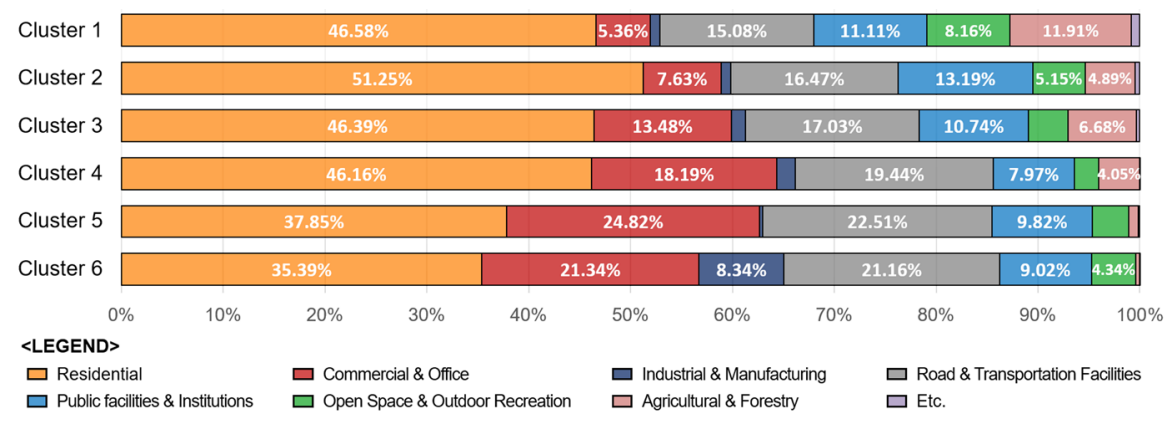

Fig. 7 Land use portfolio of each cluster

Understanding the land use mix in Seoul helps contextualizing these findings. Overall, land use mix in station catchment area within $500 \mathrm{~m}$ radius consist of, in descending order, residential area, road and transportation facilities, commercial and office area, and public facilities and institutions (Fig. 7). Simply classifying the six clusters into categories based on ridership levels, catchment area of larger-scale stations (Clusters 4, 5, 6) have higher proportion of commercial and office area, industrial and manufacturing area, and road and transportation facilities than that of smaller-scale stations (Clusters 1, 2, 3). In contrast, the catchment area of smallerscale stations have higher proportion of agricultural and forestry area, public facilities and institutions, and residential area than that of larger-scale stations.

\subsection{Multiple regression}

To assess the viability of compact cities against shocks like COVID-19, this study analyzed the association between subway ridership decline and land use mix, a key feature of compact cities. Controlling sociodemographic and station attribute variables, Model 1 suggests that land use mix is associated with the reduction in subway ridership after COVID-19, confirming previous findings that higher degree of diversity in land use positively contributes to subway usage (Choi et al. 2012). This result reverses in the context of COVID-19, during which subway ridership decreased in highly mixed land use areas. As such, land use mix appears to affect the overall volatility of ridership levels.

From the full model, Model 2, statistically significant variables with the highest coefficients are Pempl_accfood (4.343), Proad_transpfac (2.583), Ppublfac_instit (1.554), Pcomm_office (1.256), Landusemix (0.747), Transfer (0.719), Busstop (0.015), Activitydens (0.011). Controlling various land use classifications, the coefficient of the land use mix index (Landusemix) decreases, but its statistical significance is retained as was in Model 1. Model 2's result for land use mix index demonstrates that other land use classifications that are not controlled in this model exist in compact cities like Seoul; therefore, people's mobility may be restricted by risks like COVID-19 in areas with diverse land use, notably compact cities.

Of the land use variables, the ratio of road and transportation facilities area to total land area (Proad_transpfac) could stand for accessibility in a catchment area since it 
supports on-ground modes of travel alternative to subways, such as personal vehicles, taxi, and bikes. Model 2 results show that Proad_transpfac is statistically significant with positive impact on subway ridership decline. In line with other studies (Abdullah et al. 2020; Teixeira and Lopes 2020), this result implies that areas with higher accessibility via non-subway travel modes faced greater decline in subway ridership after the COVID-19 outbreak. On the other hand, the ratio of public facilities and institutions (Ppublfac_instit), also statistically significant and positively associated with ridership decline, appear to reflect the impact of COVID-19 risk management interventions - transitioning to remote learning for schools and limiting access to multipurpose facilities like sports stadiums-on reducing mobility overall. Similarly, the ratio of commercial area and office space to total land area (Pcomm_office), statistically significant and positively associated with ridership decline, further contextualize the impact of government COVID-19 prevention measures on reducing mobility. For instance, restrictions on accommodation and food services discouraged large gatherings likely reduced traffic in commercial areas. Likewise, transition to remote work following the government's escalation of the risk alert level to Red likely led to reduced crowding in areas with significant office space.

Other than land use variables, the ratio of jobs in accommodation and food services industry to total jobs (Pempl_accfood) had the largest statistically significant impact on the decline in subway ridership after the COVID-19 outbreak. This result could be credited to the Korean national and Seoul's municipal COVID-19 risk management interventions, which included social distancing measures and restrictions on operation of restaurants, cafes, and other multi-purpose facilities. More specifically, these restrictions mandated earlier facility closing, limited indoor dining, and shutdown of large-scale facilities. When COVID-19 cases peaked to anomalously high records, these measures were complemented by more austere measures restricting the use of public facilities and gatherings were imposed. Complementing these measures, the public's risk perception toward multi-purpose facilities seemed to have been high during the pandemic (Kim et al. 2021). As such, the impact of Pempl_accfood on ridership decline could be explained by constrained mobility due to restriction guidelines and the public's high risk perception of COVID-19.

Activity density (Activitydens) had a relatively smaller coefficient but was statistically significant. This result signifies that subway usage is lowered in areas with high activity density, which corresponds to past findings that activity density is associated with COVID-19 infection and mortality rates (Hamidi et al. 2020). Other sociodemographic variables pertaining age help contextualize whether ridership pattern is associated with working population (P20to64) and retired-age population (P65over) per past studies that identified reduced ridership among retired-age population during COVID-19 (Park and Cho 2021). Model 2 results reveal that these variables are not statistically significant, but their coefficient measures indicate some influence on reduced ridership during the pandemic. In a city with high subway modal share, Seoul's subway modal share at $41.6 \%$ in 2019 , the impact of both working and nonworking populations on ridership decline suggests that modal shift may be one of individuals' behavioral changes resulting from the COVID-19 outbreak.

Together, variables for the number of bus stops in catchment area (Busstop) and transferability (Transfer), show modal shift that alludes to connectivity among 
Table 5 Regression analysis results

\begin{tabular}{|c|c|c|c|c|c|c|}
\hline \multirow[t]{2}{*}{ Variable } & \multicolumn{3}{|l|}{ Model 1} & \multicolumn{3}{|l|}{ Model 2} \\
\hline & Coef & SE & $\mathrm{p}$-value & Coef & SE & $\mathrm{p}$-value \\
\hline Constant & 11.021 & 1.068 & $0.000 * * *$ & 10.753 & 1.140 & $0.000 * * *$ \\
\hline \multicolumn{7}{|l|}{ Land use } \\
\hline Landusemix & 1.397 & 0.318 & $0.000 * * *$ & 0.747 & 0.378 & $0.049 * *$ \\
\hline Pcomm_office & & & & 1.256 & 0.630 & $0.047 * *$ \\
\hline Proad_transpfac & & & & 2.583 & 0.956 & $0.007 * *$ \\
\hline Pindustry_manuf & & & & 0.289 & 0.951 & 0.762 \\
\hline Ppublfac_instit & & & & 1.554 & 0.467 & $0.001 * *$ \\
\hline Popensp_rec & & & & 0.002 & 0.655 & 0.998 \\
\hline \multicolumn{7}{|l|}{ Station attributes } \\
\hline Busstop & 0.010 & 0.006 & $0.083^{*}$ & 0.015 & 0.006 & $0.011^{*}$ \\
\hline Transfer & 0.821 & 0.117 & $0.000 * * *$ & 0.719 & 0.116 & $0.000 * * *$ \\
\hline \multicolumn{7}{|l|}{ Sociodemographic } \\
\hline Activitydens & 0.016 & 0.003 & $0.000 * * *$ & 0.011 & 0.004 & $0.003 * * *$ \\
\hline P20to64 & 1.987 & 1.371 & 0.148 & 1.824 & 1.380 & 0.187 \\
\hline P65over & 1.241 & 1.646 & 0.451 & 1.164 & 1.700 & 0.494 \\
\hline Pempl_accfood & 3.731 & 0.947 & $0.000 * * *$ & 4.343 & 0.956 & $0.000 * * *$ \\
\hline Obs (N) & 293 & & & 293 & & \\
\hline $\mathrm{R}^{2}$ & 0.388 & & & 0.441 & & \\
\hline Adj. $\mathrm{R}^{2}$ & 0.373 & & & 0.417 & & \\
\hline F-test & $25.82 * * *$ & & & $18.40 * * *$ & & \\
\hline $\begin{array}{l}\text { Breusch-Pagan/Cook- } \\
\text { Weisberg test for } \\
\text { heteroskedasticity }\end{array}$ & $\chi_{(1)}^{2}=0.25(0.6163)$ & & & $\chi_{(1)}^{2}=0.26(0.6127)$ & & \\
\hline
\end{tabular}

Unlike stations used in the clustering analysis, stations analyzed for the regression analysis exclude three stations with increased ridership after the COVID-19 outbreak

different travel modes. Both variables are statistically significant and are positively associated with ridership decline, indicating that stations located in area with fluid modal shift between bus and subway experienced ridership decline during the pandemic. This result aligns with other findings that confirm positive impact of intermodal network on subway ridership (Cervero 1996; Lee et al. 2013). Of the two, the impact of Transfer was stronger than that of Busstop, suggesting that shift within same travel mode leaves greater impact on ridership change than shift between different travel modes (Guo and Wilson 2007) (Table 5).

\section{Conclusion}

Despite much government effort spent on controlling and mitigating the risk of COVID-19 around the world, the impact of COVID-19 is yet to be overcome. Metropolitan cities have been particularly susceptible to large-scale outbreaks, 
highlighting the need for multifaceted and sustainable solutions in compact cities that can stand the test of time, and shocks, in the post-COVID-19 era.

To address this need, this study first examined the relationship between COVID-19 outbreaks, government interventions, and subway ridership in Seoul and NYC, two compact cities that experienced different trends of disease outbreaks and management at the onset of the pandemic. Dynamic analysis of the three factors confirmed that individual mobility, disease transmission, and government interventions are closely related. Then, the study proceeded to a timeseries clustering analysis of all 296 subway stations in Seoul, generating six clusters based on change in ridership level over time. The clustering analysis confirmed some association between disease outbreak and overcrowding, unmasking the vulnerability of compact cities in the face of highly transmittable diseases.

Finally, the multiple regression analysis with one model controlling for land use classification factors and another fully modeling all variables evaluated the association between subway ridership and factors related to the built environment, land use mix, population demographics, and station attributes of the catchment area surrounding the station. First, the regression analysis identified the negative impact of land use mix on ridership. Since diverse land use mix is the essence of optimizing the efficiency of compact urban form, this result suggests that compact cities may not be sustainable in face of extended exposure to risks as exemplified by the COVID-19 pandemic. This implication could be further applied to understanding the vulnerability of compact urban forms to disasters, which could leave disproportionate impact in areas where human livelihoods and the natural and built environment are densely intertwined. Based on this study's finding, this trend lays vulnerable to non-transient risks like COVID-19.

As such, strategies to mitigate risks in highly dense urban forms reliant on mixed land use need to be developed. Considering the role of land use mix observed in this study, a strategy that reconfigures the distribution of land use purposes could be effective. For instance, urban forms with some degree of polycentricity and decentralization would help mitigate and disperse risks like COVID-19, which is aggravated by physical contact. Such a strategy could be actualized by optimizing the number of urban centers and subcenters based on a respective city's scale and characteristics such as the metropolitan population, activity population, and employment density. Polycentricity alone cannot define the resilience of a city, but combined with factors like connectivity, measures like the number of urban centers and subcenters could serve as an indicator for resilient and sustainable urban forms in future planning practices and research. Future studies could further investigate different urban spatial structures and characteristics that could improve resilience to such long-term risks in more comprehensive ways.

Future studies could also address several limitations of this study. First, ridership pattern studies typically utilize hourly turnstile data, but such data were inaccessible for both Seoul and New York City. Second, the clustering and regression analysis only pertained to Seoul. To widen the array of knowledge about compact cities, other cities with compact urban form need to be analyzed additionally. Finally, studies on transportation modes other than subways and long-term trends in modal shift based on changes in mobility patterns of compact cities in the context of COVID-19 could enrich the literature on this topic. 


\section{Appendix}

See Fig. 8.

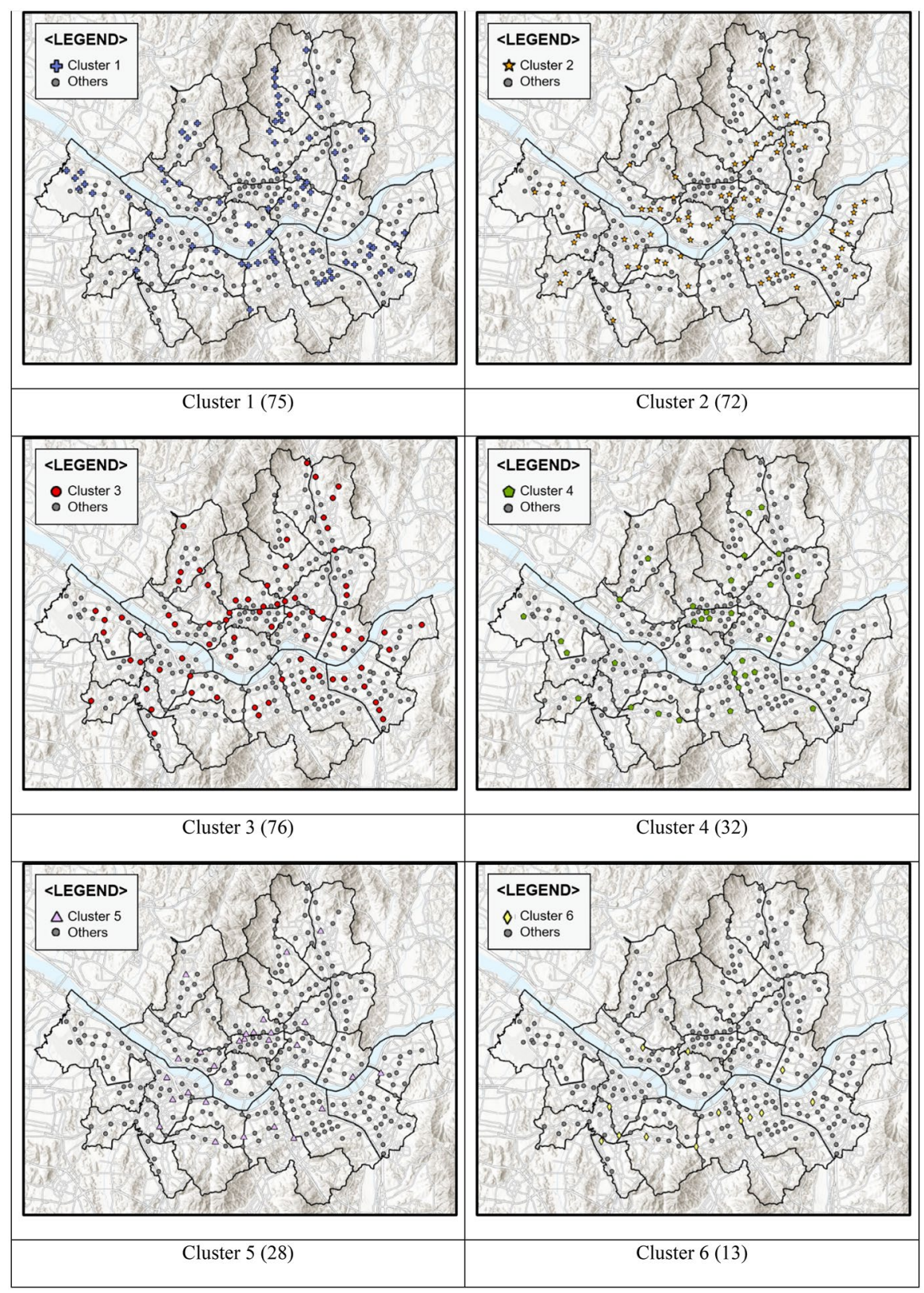

Fig. 8 Spatial Distribution for Cluster 1 to Cluster 6 
Acknowledgements This research was supported by Seoul National University Research Grant in 2020.

\section{References}

Abdullah M, Dias C, Muley D, Shahin M (2020) Exploring the impacts of COVID-19 on travel behavior and mode preferences. Transp Res Interdiscip Perspect 8:100255

Abdullah M, Ali N, Hussain SA, Aslam AB, Javid MA (2021) Measuring changes in travel behavior pattern due to COVID-19 in a developing country: a case study of Pakistan. Transp Policy 108:21-33

Abodunrin O, Oloye G, Adesola B (2020) Coronavirus pandemic and its implication on global economy. Int J Arts Lang Bus Stud 4:13-23

Amin TB, Mahmood I (2008) Speech recognition using dynamic time warping. In: 2008 2nd international conference on advances in space technologies, pp 74-79. IEEE

Atkinson G, Oleson T (1996) Urban sprawl as a path dependent process. J Econ Issues 30(2):609-615

Bahney A (2020) Manhattan had 15,000 empty apartments in August-a new record. CNN Business. September 10th. Retrieved December 14, 2020, from https://edition.cnn.com/2020/09/10/success/ manhattan-rental-apartment-vacancy- rate/index.html.

Barnes KB, Morgan JM III, Roberge MC, Lowe S (2001) Sprawl development: its patterns, consequences, and measurement. Towson Univ Towson 1:24

Bellman R, Kalaba R (1959) On adaptive control processes. IRE Trans Autom Control 4(2):1-9

Bhadra A, Mukherjee A, Sarkar K (2021) Impact of population density on Covid-19 infected and mortality rate in India. Model Earth Syst Environ 7(1):623-629

Bhaduri E, Manoj BS, Wadud Z, Goswami AK, Choudhury CF (2020) Modelling the effects of COVID19 on travel mode choice behaviour in India. Transp Res Interdiscip Perspect 8:100273

Bhat CR, Guo JY (2007) A comprehensive analysis of built environment characteristics on household residential choice and auto ownership levels. Trans Res Part B Methodol 41(5):506-526

Bian Z, Zuo F, Gao J, Chen Y, Venkata SSCP, Bernardes SD (2021) Time lag effects of COVID-19 policies on transportation systems: a comparative study of New York City and Seattle. Transp Res Part A Policy Pract 145:269-283

Bibri SE, Krogstie J, Kärrholm M (2020) Compact city planning and development: Emerging practices and strategies for achieving the goals of sustainability. Dev Built Environ 4:100021

Bramley G, Power S (2009) Urban form and social sustainability: the role of density and housing type. Environ Plann B Plann Des 36(1):30-48

Breheny M (1997) Urban compaction: feasible and acceptable? Cities 14(4):209-217

Breheny M (1995) The compact city and transport energy consumption. Trans Inst British Geograph, pp $81-101$

Brodeur A, Clark AE, Fleche S, Powdthavee N (2021) COVID-19, lockdowns and well-being: evidence from Google Trends. J Public Econ 193:104346

Brueckner JK (2000) Urban sprawl: diagnosis and remedies. Int Reg Sci Rev 23(2):160-171

Bucsky P (2020) Modal share changes due to COVID-19: the case of Budapest. Transp Res Interdiscip Perspect 8:100141

Burger M, Meijers E (2012) Form follows function? Linking morphological and functional polycentricity. Urban Studies 49(5):1127-1149

Burton E (2002) Measuring urban compactness in UK towns and cities. Environ Plann B Plann Des 29(2):219-250

Cao Z, Asakura Y, Tan Z (2020) Coordination between node, place, and ridership: comparing three transit operators in Tokyo. Transp Res Part D: Transp Environ 87:102518

Carruthers JI, Ulfarsson GF (2003) Urban sprawl and the cost of public services. Environ Plann B Plann Des 30(4):503-522

Celebi S, Aydin AS, Temiz TT, Arici T (2013) Gesture recognition using skeleton data with weighted dynamic time warping. In VISAPP vol 1, pp 620-625

U.S. Census Bureau (2020) Sex workers by means of transportation to work for workplace geography, 2019 ACS 5-years estimates detailed tables. The Census Bureau. https://data.census.gov/cedsci/ table?q=B08406\%20NEW\%20YORK\%20CITY\&tid=ACSDT5Y2019.B08406

U.S. Census Bureau (2021) Population per square mile, QuickFacts. The Census Bureau. https://www. census.gov/quickfacts/fact/table/newyorkcitynewyork,NY/POP060210\#POP060210 
Cervero R (1996) Mixed land-uses and commuting: evidence from the American Housing survey. Transp Res Part A Policy Pract 30(5):361-377

Cervero R, Kockelman K (1997) Travel demand and the 3Ds: density, diversity, and design. Transp Res Part d: Transp Environ 2(3):199-219

Chen C, Chen J, Barry J (2009) Diurnal pattern of transit ridership: a case study of the New York City subway system. J Transp Geogr 17(3):176-186

Choi J, Lee YJ, Kim T, Sohn K (2012) An analysis of Metro ridership at the station-to-station level in Seoul. Transportation 39(3):705-722

Choi S, Choo S, Kim S (2020) Exploring the influences of compact development on zone-based travel patterns: a case study of the Seoul metropolitan area. Transp Lett 12(5):316-328

Ciscel DH (2001) The economics of urban sprawl: inefficiency as a core feature of metropolitan growth. J Econ Issues 35(2):405-413

Clarke K (2020) COVID-19 Pounds New York Real Estate Worse Than 9/11, Financial Crash. The Wall Street J. August 20th. Retrieved December 14, 2020, from https://www.wsj.com/articles/covid-19new-york-real-estate-11597939146.

Collyer S, Huq S, Washington K, Wilmer C (2020) Spotlight on COVID-19: Nearly half of all New York City workers lost employment income from the pandemic, deepening economic insecurity and racial inequity across the city. Available from https://www.robinhood.org/wp-content/themes/robin hood/images/poverty-tracker/poverty_tracker.pdf.

Creswell J, Eavis P (2020) Manhattan's Office Buildings Are Empty. But for How Long? New York Times. September 8th. Retrieved September, 2020, from https://www.nytimes.com/2020/09/08/ business/economy/new-york-office-space-coronavirus.html?referringSource=articleShare.

De Roo G (2000) Environmental conflicts in compact cities: complexity, decisionmaking, and policy approaches. Environ Plann B Plann Des 27(1):151-162

Decoville A, Klein O (2020) Polycentrism and the accessibility of public facilities to the population. The example of the Grand Duchy of Luxembourg and Belval. Eur Plan Stud 28(4):653-671

Dempsey N, Brown C, Bramley G (2012) The key to sustainable urban development in UK cities? The influence of density on social sustainability. Prog Plan 77(3):89-141

Deng FF, Huang Y (2004) Uneven land reform and urban sprawl in China: the case of Beijing. Prog Plan 61(3):211-236

Dieleman F, Wegener M (2004) Compact city and urban sprawl. Built Environ 30(4):308-323

Dubay L, Aarons J, Brown KS, Kenney GM (2020) How risk of exposure to the coronavirus at work varies by race and ethnicity and how to protect the health and well-being of workers and their families. Health Policy Center, Res Rep

Ewing R, Tian G, Goates JP, Zhang M, Greenwald MJ, Joyce A, Kircher J, Greene W (2015) Varying influences of the built environment on household travel in 15 diverse regions of the United States. Urban Stud 52(13):2330-2348

Frumkin H, Frank L, Frank LD, Jackson RJ (2004) Urban sprawl and public health: designing, planning, and building for healthy communities. Island Press

Giuliano G, Small KA (1991) Subcenters in the Los Angeles region. Reg Sci Urban Econ 21(2):163-182

Glaeser EL, Gorback C, Redding SJ (2020) How much does COVID-19 increase with mobility? Evidence from New York and four other U.S. cities. NBER working paper (w27519)

Gordon P, Kumar A, Richardson HW (1989) The influence of metropolitan spatial structure on commuting time. J Urban Econ 26(2):138-151

Grant P, Tucker E (2020) Manhattan Offices are nearly empty, threatening New York City's Recovery, The Wall Street J. September 29th. Retrieved November 2, 2020, from https://www.wsj.com/artic les/manhattan-offices-are-nearly-empty-threatening-new-york-citys-recovery-11601371800.

Guo Z, Wilson NH (2007) Modeling effects of transit system transfers on travel behavior: case of commuter rail and subway in Downtown Boston, Massachusetts. Transp Res Rec 2006(1):11-20

Gutiérrez J, Cardozo OD, García-Palomares JC (2011) Transit ridership forecasting at station level: an approach based on distance-decay weighted regression. J Transp Geogr 19(6):1081-1092

Hall SG, Ashley WS (2008) Effects of urban sprawl on the vulnerability to a significant tornado impact in northeastern Illinois. Nat Hazard Rev 9(4):209-219

Hamidi S, Ewing R (2014) A longitudinal study of changes in urban sprawl between 2000 and 2010 in the United States. Land Urban Plan 128:72-82

Hamidi S, Sabouri S, Ewing R (2020) Does density aggravate the COVID-19 pandemic? Early findings and lessons for planners. J Am Plann Assoc 86(4):495-509

Han J, Pei J, Kamber M (2011) Data mining: concepts and techniques. Elsevier 
Harris JE (2020) The subways seeded the massive coronavirus epidemic in New York city. NBER working paper (w27021)

Hawkins D (2020) Differential occupational risk for COVID-19 and other infection exposure according to race and ethnicity. Am J Ind Med 63(9):817-820

Hofstad H (2012) Compact city development: High ideals and emerging practices. Eur J Spat Dev $10(5): 23-23$

Holcombe RG, Williams DW (2010) Urban sprawl and transportation externalities. Rev Region Stud 40(3):257-273

Hortas-Rico M, Solé-Ollé A (2010) Does urban sprawl increase the costs of providing local public services? Evidence from Spanish municipalities. Urban Studies 47(7):1513-1540

Huang VS, Sutermaster S, Caplan Y, Kemp H, Schmutz D, Sgaier SK (2020) Social distancing across vulnerability, race, politics, and employment: How different Americans changed behaviors before and after major COVID-19 policy announcements. medRxiv

Jabareen YR (2006) Sustainable urban forms: their typologies, models, and concepts. J Plan Educ Res 26(1):38-52

Johnson MP (2001) Environmental impacts of urban sprawl: a survey of the literature and proposed research agenda. Environ Plan A 33(4):717-735

Kamga C, Moghimi B, Vicuna P, Mudigonda S, Tchamna R (2020) Mobility trends in New York City during COVID-19 pandemic: analyses of transportation modes throughout June 2020. Available from http://www.utrc2.org/sites/default/files/Mobility\%20Report\%20in\%20NYC\%20\%20COV ID19_June_2020.pdf.

Kaufman L, Rousseeuw PJ (2009) Finding groups in data: an introduction to cluster analysis, vol 344. John Wiley \& Sons

Keogh EJ, Pazzani MJ (1999) Scaling up dynamic time warping to massive datasets. In European conference on principles of data mining and knowledge discovery. Springer, Berlin

Kim MK, Kim SP, Heo J, Sohn HG (2017) Ridership patterns at subway stations of Seoul capital area and characteristics of station influence area. KSCE J Civ Eng 21(3):964-975

Kim D, Park J, Hong A (2018) The role of destination's built environment on nonmotorized travel behavior: a case of long beach, california. J Plan Educ Res 38(2):152-166

Kim MH, Lee J, Gim THT (2021) How did travel mode choices change according to coronavirus Disease 2019? Lessons from Seoul, South Korea. Int J Urban Sci 25(3):437-454

Kloosterman R, Musterd S (2001) The polycentric urban region: Towards a research agenda. Urban Stud 38(4):623-633

Korea Centers for Disease Control \& Prevention (2020) Infectious disease press release. (in Korean) March 22nd. Retrieved December 11, 2020, from http://www.kdca.go.kr/npt/biz/npp/portal/nppIs sueIcdView.do?issueIcdSn=338.

Kuby M, Barranda A, Upchurch C (2004) Factors influencing light-rail station boardings in the United States. Transp Res A Policy Pract 38(3):223-247

Lee S, Yi C, Hong SP (2013) Urban structural hierarchy and the relationship between the ridership of the Seoul Metropolitan Subway and the land-use pattern of the station areas. Cities 35:69-77

Li S, Lyu D, Liu X, Tan Z, Gao F, Huang G, Wu Z (2020b) The varying patterns of rail transit ridership and their relationships with fine-scale built environment factors: Big data analytics from Guangzhou. Cities 99:102580

Li A, Zhao P, He H, Axhausen KW (2020a) Understanding the variations of micro-mobility behavior before and during COVID-19 pandemic period. Arbeitsberichte Verkehrs-und Raumplanung 1547

MacQueen J (1967) Some methods for classification and analysis of multivariate observations. In: Proceedings of the fifth Berkeley symposium on mathematical statistics and probability, vol 1, No 14, pp 281-297

Manley E, Ross S, Zhuang M (2021) Changing demand for New York yellow cabs during the COVID-19 pandemic. Findings 22158

McDonald JF (1987) The identification of urban employment subcenters. J Urban Econ 21(2):242-258

Mileti D (1999) Disasters by design: a reassessment of natural hazards in the United States. Joseph Henry Press

Nechyba TJ, Walsh RP (2004) Urban sprawl. J Econ Perspect 18(4):177-200

Nilles JM (1991) Telecommuting and urban sprawl: mitigator or inciter? Transportation 18(4):411-432

NYC Department of Planning (2019) The ins and outs of NYC commuting, an examination of recent trends and characteristics of commuter exchanges between NYC and the surrounding Metro 
Region. Available from https://www1.nyc.gov/assets/planning/download/pdf/planning-level/housi ng-economy/nyc-ins-and-out-of-commuting.pdf.

OECD (2020) OECD policy responses to coronavirus (COVID-19): cities policy responses. Tackling coronavirus (COVID-19): contributing to a global effort. OECD.

Office of New York City Comptroller (2021) The pandemic's impact on NYC migration patterns. Available from https://comptroller.nyc.gov/wp-content/uploads/documents/The-Pandemics-Impact-onNYC-Migration-Patterns.pdf.

Park K, Ewing R, Sabouri S, Choi DA, Hamidi S, Tian G (2020) Guidelines for a polycentric region to reduce vehicle use and increase walking and transit use. J Am Plann Assoc 86(2):236-249

Park B, Cho J (2021) Older Adults' avoidance of public transportation after the outbreak of COVID19: Korean subway evidence. In: Healthcare (vol 9, No. 4). Multidisciplinary Digital Publishing Institute

Park J (2020) Changes in subway ridership in response to COVID-19 in Seoul, South Korea: implications for social distancing. Cureus 12(4):e7668

Pawar DS, Yadav AK, Akolekar N, Velaga NR (2020) Impact of physical distancing due to novel coronavirus (SARS-CoV-2) on daily travel for work during transition to lockdown. Transp Res Interdiscip Perspect 7:100203

Polyakova M, Kocks G, Udalova V, Finkelstein A (2020) Initial economic damage from the COVID-19 pandemic in the United States is more widespread across ages and geographies than initial mortality impacts. Proc Natl Acad Sci 117(45):27934-27939

Rérat P (2012) Housing, the compact city and sustainable development: Some insights from recent urban trends in Switzerland. Int J Hous Policy 12(2):115-136

Ribeiro HV, Sunahara AS, Sutton J, Perc M, Hanley QS (2020) City size and the spreading of COVID-19 in Brazil. PLoS ONE 15(9):e0239699

Riguelle F, Thomas I, Verhetsel A (2007) Measuring urban polycentrism: a European case study and its implications. J Econ Geograph 7(2):193-215

Scull J, Phillips M, Sharma U, Garnier K (2020) Innovations in teacher education at the time of COVID19: an Australian perspective. J Educat Teach 46(4):497-506

Seoul Metropolitan Government (2020) Main Transportation Statistics: Transportation Modal Share. SMG Transportation. (in Korean). August 18th. https://news.seoul.go.kr/traffic/archives/289.

Seoul Open Data Plaza (2021) Statistics of the residential and daytime population in Seoul. Available from https://data.seoul.go.kr/dataList/10077/S/2/datasetView.do

Sharifi A (2019) Resilient urban forms: a macro-scale analysis. Cities 85:1-14

Shamshiripour A, Rahimi E, Shabanpour R, Mohammadian AK (2020) How is COVID-19 reshaping activity-travel behavior? Evidence from a comprehensive survey in Chicago. Transp Res Interdiscip Perspect 7:100216

Sharma A, Sundaram S (2017) On the exploration of information from the DTW cost matrix for online signature verification. IEEE Trans Cybern 48(2):611-624

Statistics Korea (2021) Regional population and population density. E-nara index. https://www.index.go. $\mathrm{kr} /$ potal/main/EachDtlPageDetail.do?idx_cd=1007

Sung H, Oh JT (2011) Transit-oriented development in a high-density city: identifying its association with transit ridership in Seoul, Korea. Cities 28(1):70-82

Teixeira JF, Lopes M (2020) The link between bike sharing and subway use during the COVID-19 pandemic: the case-study of New York's Citi Bike. Transp Res Interdiscip Perspect 6:100166

US Bureau of Labor Statistics (2021) Higher paid workers more likely than lower paid workers to have paid leave benefits in 2020. https://www.bls.gov/opub/ted/2021/higher-paid-workers-more-likelythan-lower-paid-workers-to-have-paid-leave-benefits-in-2020.htm

Veneri P, Burgalassi D (2012) Questioning polycentric development and its effects. Issues of definition and measurement for the Italian NUTS-2 regions. Eur Plan Stud 20(6):1017-1037

Wang W, Lyu G, Shi Y, Liang X (2018) Time series clustering based on dynamic time warping. In: 2018 IEEE 9th international conference on software engineering and service science (ICSESS), pp 487-490. IEEE

Westerink J, Haase D, Bauer A, Ravetz J, Jarrige F, Aalbers CB (2013) Dealing with sustainability trade-offs of the compact city in peri-urban planning across European city regions. Eur Plan Stud 21(4):473-497

World Health Organization (2020) WHO Coronavirus Disease (COVID-19) Dashboard. WHO. Retrieved December 13, 2020, from https://covid19.who.int/?gclid=CjwKCAiAt9z-BRBCEiwA_bWvL5NqWz1rYzZwH9CUWxazu0sPj63hnlosFMLIEK4LEOBx-zt_EM0mBoCyGIQAvD_BwE. 
Ye Q, Ozbay K, Zuo F, Chen X (2021) impact of social media on travel behaviors during the COVID-19 pandemic: evidence from New York City. Transp Res Record 03611981211033857

Publisher's Note Springer Nature remains neutral with regard to jurisdictional claims in published maps and institutional affiliations. 